\title{
Curriculum Reform in Irish Secondary Schools - A Focus on Algebra
}

\begin{abstract}
Algebra has long been identified as an area of difficulty in the teaching and learning of mathematics. Evidence of this difficulty can be found in Irish secondary level classrooms. Chief Examiner Reports have consistently identified algebra as an area of student weakness in State examinations. In light of poor student performance, and as part of a nationwide reform of secondary mathematics curricula, a functions based approach to teaching algebra has been adopted in Irish schools. It was introduced in September 2011 in place of the transformational (rule and procedure) based approach which was previously used. Through comparing the diagnostic test scores of incoming students in an Irish university in the years before and after the reform, this study finds that the reformed approach has coincided with a decline in students' technical algebraic skills. However interviews with practicing mathematics teachers reveal that this decline is not a direct result of the functions based approach, but rather of a mixture of approaches being implemented in classrooms. Such divergence of approaches can be linked to the common mismatch between the intended curriculum prescribed by policy makers and the implemented curriculum that is actually carried out by teachers in their classrooms.
\end{abstract}

Keywords: curriculum reform; algebra; functions approach; secondary level

\section{Introduction}

In September 2011, as part of a phased nationwide reform of the secondary mathematics curricula, a functions based approach to teaching algebra was promoted in Irish classrooms. It was adopted in place of the transformational (rule and procedure) based approach which was previously used. One of the aims of this study is to investigate the immediate effect (if any) that this change in curricular approach has had on Irish students' transformational algebraic ability. This will be done through analysing the results of a diagnostic test taken by incoming first year students at an Irish university. The diagnostic test at the University of Limerick (UL) is made up of forty questions, eight of which are based on algebra. The diagnostic results of incoming first year students between the years 
$2009-2011$ will be compared with the results of students from $2012-2014$. These years were selected as the algebra strand of the reformed curriculum was introduced in September 2011. Hence the students who took the UL diagnostic test between the years 2009 - 2011 should have been taught algebra using the transformational approach while those in 2012 - 2014 should have been taught using the newly adopted functions based approach. The authors argue that irrespective of approach, there should be no difference in students' basic algebraic skills. The knowledge base for procedures such as rearranging formulae, expanding brackets, substitution and solving equations remains important regardless of whether students are being taught algebra using a transformational, a functions based, or indeed any other approach. These skills have long been a hallmark of algebraic proficiency and anyone who lacks a solid grasp of such concepts is significantly disadvantaged in mathematics (Schoenfeld, 2007).

The second aim of this study is to explore teachers' views on the reformed approach. It is well documented that teachers have a central role in the successful adoption of any curriculum reform (Kärkkäinen, 2012; Schoenfeld, 2014). Consequently, it is important to consider teachers' views and perceptions towards the adoption of the functions based approach to teaching algebra. This will be done through interviews with five practicing mathematics teachers.

\section{Mathematics Curricula Reform}

Since the middle of the $20^{\text {th }}$ century, there have been significant on-going shifts in the structure, content, and core principles of mathematics curricula in countries around the world (Schoenfeld, 2014; Krupa \& Confrey, 2015). For example in 1980 in the U.S., the National Council of Teachers of Mathematics (NCTM) necessitated a move away from the emphasis that the 'New Maths' movement of the 1960's had placed on skills and 
procedures. Their report entitled an 'Agenda for Action' placed problem solving at the centre of school mathematics (Klein, 2007). This was built on by the NCTM (1989) 'Standards' report which endorsed student-centred, discovery learning through real world problems (Klein, 2007). However calls for increased levels of accountability and changes such as the No Child Left Behind Act in 2001, prompted greater focus on standardised testing in U.S. mathematics education with a de-emphasis of reasoning and problem solving. More recently, the widespread adoption of the Common Core State Standards in Mathematics in 2010 indicates that there may be a return to the focus on problem solving and placing mathematics in context (Schoenfeld, 2014).

In Japan and China, influences of Western countries have also led to greater emphasis on problem solving within their respective curricula. In 1989, Japan began to place mathematics problems in more familiar contexts in order to develop students' appreciation of mathematics and encourage its use in their daily lives (Koyama, 2010). In a similar fashion in 2001, China reduced the emphasis on acquisition of knowledge and skills, instead focussing on the development of positive attitudes and linking content to student interests and experiences ( $\mathrm{Liu} \& \mathrm{Li}, 2010)$.

Despite the significant reforms that were taking place internationally, Ireland had remained relatively removed from such developments. The curriculum was largely unchanged from the 1960's and emphasised mathematical structures, abstraction and rigorous presentation (Lyons, Lynch, Close, Sheerin, \& Boland, 2003). This resulted in a highly didactic and procedural approach to mathematics teaching at secondary level in Ireland which caused many issues (National Council of Curriculum and Assessment (NCCA), 2005). These issues such as an over-reliance on rote learning and an assessment led curriculum were highly publicised and the Government were forced into action with a major reform of all secondary mathematics curricula taking place (Prendergast, 
Faulkner, Breen, \& Carr, 2017). The reform entitled 'Project Maths' was rolled out in all schools on a phased basis beginning in September 2010. It's implementation involved changes to what students learn in mathematics, how they learn it and how they are assessed (Prendergast \& O'Meara, 2016). One of the areas of mathematics that was subject to much change was the teaching and learning of algebra.

\section{A Focus on Algebra in the School Curriculum}

There is little doubt that algebra is a pivotal part of school mathematics curricula around the world (Huntley, Marcus, Kahan, \& Lincoln Miller, 2007). Success in the topic is considered a gatekeeper to further education and employment opportunities (National Mathematics Advisory Panel, 2008). However despite such importance, differing views have been expressed on what school algebra actually is, and what defines algebraic thinking (Kieran, 2014). This has resulted in differences in the algebra content taught in schools (Kilpatrick \& Izsák, 2008). For example, traditional algebra classrooms have been characterised as places where students focus on procedures for symbol manipulation but not on underlying meanings (Chazan, 2000).

While part of the power of algebra comes from the ability to work with symbolic forms, this provides a limited perspective of algebra which does not include thinking about its use or its practical value (Kilpatrick \& Izsák, 2008). Decades ago, Freudenthal (1977) defined school algebra as the solving of equations but also the ability to describe the procedures used in solving problems and the mathematical relations that support these processes. This definition remains relevant today because it captures not only the symbolic aspects of algebraic activity but also the kinds of relational thinking that underlie algebraic reasoning (Kieran, 2014). With this in mind, reform efforts in the U.S., Australia and Japan over the past few decades have led to the development of a functions 
based approach to school algebra that emphasises relationships between variables and multiple representations of functions as an alternative to the more traditional rule-based approaches (Kieran, 2014).

\section{The Functions Based Approach to School Algebra}

Functional thinking is a key aspect of algebraic thinking because it involves understanding the notion of change and making generalisations about how two or more varying quantities such as patterns of number sequences are related (Tanish, 2011). For example, students can be presented with problems in some kind of context such as familiar everyday situations, imaginary scenarios or even arrangements of tiles or blocks. The functions based approach involves looking for patterns in these contexts for how different quantities vary in relation to each other (Blanton, 2008). Students can express any variations through functions using algebraic symbols such as variables to represent quantities and subsequent expressions to represent rules. These rules are functional relationships formed by calculating the output values of given input values and generalising so some values can be determined accordingly (Lannin, Barker, \& Townsend, 2006). This is the first step in expressing functions by using variables and expressions (Ley, 2005). It is important to note that while this approach values the ability to work with symbolic form, it also enables students to appreciate the use and value of algebra. For example, the functions can be displayed on the Cartesian plane as a space to display and consider a variety of meanings of the results (Chazan \& Yerushalmy, 2003). Therefore students represent the problem using a rich set of tools such as words, numbers, symbols, tables and graphs.

\section{Algebra in Irish Secondary Schools}


Chief Examiners' Reports (1999, 2003, 2006, and 2015) have identified algebra as an area of weakness in Irish State examinations over the past number of years. According to these reports, secondary students' performance in algebra has shown little or no progress over the last fifteen years. Questions related to algebra on State examinations have been both low scoring and unpopular choices. This may be a result of the over reliance on symbol manipulation when teaching the domain with lessons traditionally dominated by transformational based activities (Prendergast \& O'Donoghue, 2014a). Such overreliance often results in students displaying a lack of understanding regarding the structure of algebra (Huntley et al., 2007). Many students learn to manipulate expressions and equations in a rote fashion (Kieran, 1992). Although such procedures and skills are important outcomes of learning algebra, what students need even more is a sound understanding of algebraic concepts and the ability to use knowledge in new and often unexpected ways (Prendergast \& O’Donoghue, 2014a).

The curricula reform of 'Project Maths' aims to provide such understanding. The reformed algebra strand was introduced to all secondary schools in September 2011. In a shift from the transformational based approach which had dominated Irish classrooms, the reformed strand follows the lead of several countries and advocates a functions based approach to teaching the domain (Prendergast \& Treacy, 2015). In line with the central aims and objectives of 'Project Maths', the reformed approach reflects inquiry methods through which students take responsibility when dealing with new problems rather than rehearsing known procedures.

The change in teaching approach has also led to a change in the assessment approach linked to the algebra strand. The assessment reflects the changes in emphasis of a functions based approach in which students are required to take an everyday problem, 
solve it mathematically using tables, functions and graphs and then interpret their results in the context of the problem (Prendergast \& Treacy, 2015).

Early evaluations of 'Project Maths' provide evidence on the positive impact of the reform on students' attitudes towards mathematics and their achievement at an individual strand level (Jeffes et al., 2013). However the same report shows that out of the five strands, algebra is in the lowest two strands both in terms of student confidence and student achievement. There is also evidence to suggest a negative attitude of some teachers towards the reform and of differences between the prescribed curriculum and what is actually being taught in Irish classrooms (Jeffes et al., 2013). Such a mismatch between the intended and implemented curriculum is a challenge which has long been associated with the enactment of educational reform in all subjects.

\section{Challenges associated with the Implementation of Educational Reform}

In education, curriculum change is a complex process and there are many associated challenges (Handal \& Herrington, 2003). There is often an expectation that a new curriculum will be adopted and implemented without difficulty in all classrooms (Scheker-Mendoza, 2011). This is based on the simplistic assumption that teachers will, machine like, alter their behaviours because they are simply told what is good for them and for their students (Handal \& Herrington, 2003). However, this is a narrow view. Several studies have highlighted how the manner in which curricula are implemented do not always reflect what curriculum designers had in mind (Smith \& Southerland, 2007; Orafi \& Borg, 2009). Teachers seldom implement a curriculum exactly as stated in curriculum policy documents (Ma, Lam, \& Wong, 2006). They further define and shape the intended learning objectives while transforming them into actual learning experiences (Scheker-Mendoza, 2011). This is often referred to as a mismatch between the intended 
and the implemented curriculum (Cuban, 1993). The intended curriculum is the one prescribed by policy makers and the implemented curriculum is the one that is actually carried out by teachers in their classrooms (Handal \& Herrington, 2003). There are a wide range of interlinking factors which can account for the divergence between the intended curriculum and the curriculum which teachers implement (Orafi \& Borg, 2009). One of the main factors in a disparity between teachers' pedagogical principles and beliefs and those underpinning the reform. Any proposed changes will have minimal impact in classrooms unless teachers' beliefs are congruent with those of the reform (Handal \& Herrington, 2003).

\section{Teachers' Views of Educational Reform}

Teachers have a central role in the successful adoption of any curriculum reform and they are often referred to as the agents of the change process (Kärkkäinen, 2012; Schoenfeld, 2014). However, they are also regarded as playing a conservative role in educational change, regularly resisting and opposing its introduction (Duke, 2004). This is because educational reform brings a certain amount of anxiety and can be very threatening to teachers (Guskey, 1986). To change or to try something new means to risk failure. Students might learn less well than they do under current practices. Hence teachers are often reluctant to adopt new practices or procedures unless they feel sure they can make them work (Lortie, 1975).

Ultimately, teachers' personal theories about teaching and learning influence how they value and implement reform curricula (Manouchehri \& Goodman, 1998). Enacting a new curriculum often demands major adjustments of teachers thinking and practices (Orafi \& Borg, 2009). This inevitably leads to concerns on pedagogical issues such as the 
reasoning behind the reform, the implications for their classroom practices, the consequences for their students, and their ability to implement the changes.

In addition to the aforementioned concerns, the literature on educational innovation has identified frequent mismatches between curricular principles and teachers' beliefs as a major obstacle to the implementation of change (Orafi \& Borg, 2009). For example, Levitt (2001) argues that “if teachers' beliefs are incompatible with the philosophy of education reform, a gap develops between the intended principles of reform and the implemented principle of reform, potentially inhibiting essential change" (p. 1). Thus curriculum innovations which conflict with teachers' beliefs are less likely to be adopted as planned in the classroom.

With this in mind, it is important for policy-makers and educators to have a clear understanding of teachers' concerns and beliefs and involve them in the reform process before and during its implementation (Fullan \& Hargreaves, 1992). Teachers must believe that any new innovation is workable and is likely to enhance their students learning (Guskey, 1986). Furthermore, the cognitive and contextual realities of teachers' work must be taken into consideration (Orafi \& Borg, 2009). If a shared vision of reform is held by all parties, efforts towards its implementation may be more likely to experience success.

Unfortunately, many educational reforms in mathematics have had a top down approach that did not take into account mathematics teachers' concerns and beliefs (Kyeleve \& Williams, 1996). Policy makers should no longer assume that curriculum implementation is a process that translates directly into the classroom reality. It is teachers who ultimately decide the fate of any educational enterprise. Consequently, their attitudes, feelings, and perceptions must be identified and any discrepancies addressed before the roll out of any reform (Handal \& Herrington, 2003). Unless this is done, 
teachers are likely to maintain their original practices in the privacy of their own classrooms (Handal \& Herrington, 2003).

This study aims to provide clarity to the following research questions:

- Has the adoption of a functions based approach to teaching algebra in Irish secondary schools had any effect on students' transformational algebraic ability?

- What are teachers' views on adopting the functions based approach?

\section{Methodology}

The authors decided to use an explanatory sequential mixed methods design approach by combining both qualitative and quantitative research. Fistly the diagnostic test scores of a goup of pre and post reform students were examined. This gave a quantiative measure of any effect that the adpotion of a functions based approach had on students' transformational algebraic ability. Secondly, interviews with five secondary teachers were carried out to determine their views on adopting the functions based approach when teaching algebra. These sequential interviews also gave the authors the opportunity to interpret and discuss the quantitative data with these key stakeholders in more detail and explore key findings from their perspective.

\section{Quantitative Section}

The diagnostic test utilised during this study, through which data was gathered and analysed, was designed in UL in 1997 to help identify students who may be at risk of failing service mathematics examinations (Gill, O’Donoghue, Hannigan,.\& Faulkner, 2010). UL is a higher education institution in Ireland with a primary focus on Science and Technology subjects. It currently has over 12,000 students and 1400 staff members with four different faculties. The largest faculty is the Science and Engineering faculty which 
consists of 10 different departments one of which is the Department of Mathematics and Statistics. The Department of Mathematics and Statistics deliver service mathematics modules to its client departments (Science, Technology, Business, Computers and Engineering). Service mathematics refers to mathematics offered to degree courses where mathematics is required, but is not the main focus of the degree. The research detailed in this article focuses on two of the service mathematics groups: Science and Technology students. There has been a large increase in the numbers of students enrolling in degree programmes which are required to do Science and Technology mathematics. In 1998, there were 507 students enrolled in Science and Technology mathematics courses, and this peaked to 739 in 2012. The increasing number of students within the Science and Technology cohorts has been due in part to the increased number of degree programmes on offer in UL; from 8 to 14 degree programmes in Technology mathematics and from 8 to 11 in Science mathematics.

The diagnostic test is administered to the Science and Technology cohorts in their first lecture and its main aim is to help recognise students who are struggling with basic mathematical concepts needed for third level mathematics study (Faulkner, Hannigan, \& Fitzmaurice, 2014). Using the results of the diagnostic test, several statistical methods for predicting performance have been explored to identify students most likely to fail firstsemester mathematics (Faulkner et al., 2014). For example, students who score 18/40 or less in this diagnostic test are considered to be under-prepared for the mathematical demands of their service mathematics module, thus they are deemed to be 'at risk'. Research by Faulkner (2012) objectively proved that setting this as the cut-off point for determining whether or not a student is 'at risk' would be an accurate prediction of their likely performance based on retrospective data. This conclusion was largely informed by the finding that, in the period $1998-2008,84.4 \%$ of students who achieved a mark of 18 
or less in the UL diagnostic test went on to fail their end-of-term examination. Students who are termed 'at risk' are encouraged to avail of mathematics support services available at the university (Treacy, Faulkner, \& Prendergast, 2016).

The design of the UL diagnostic test was carried out through analysis and adjustment of an initial list of 70 questions by a team of experienced service mathematics lecturers. These lecturers reduced this set of 70 questions to the final 40 question version used from 1997 to the present day. Thirty-four of these questions are set at a Leaving Certificate (LC) Ordinary Level standard or below, with the other six questions set at a LC Higher Level standard. The LC is the final State examination for students at secondary level in Ireland and they can sit the mathematics examination at one of three levels Higher, Ordinary, or Foundation. To ensure the validity of the diagnostic test, it was then piloted in Irish secondary schools and compared with the Irish Junior Cycle (lower secondary level) and Senior Cycle (upper secondary level) mathematics syllabi and further diagnostic tests (Gill et al., 2010).

Since 1998 students from Science Mathematics 1 and Technological Mathematics 1 have been assigned the forty question diagnostic test that assesses fundamental skills and procedures in various mathematical topics. These topics include arithmetic (13 questions), algebra (8 questions), geometry (4 questions), trigonometry (3 questions), coordinate geometry (4 questions), complex numbers (2 questions), differentiation (3 questions), integration (2 questions), and modelling (1 question). The test's layout and each of the forty questions have remained unchanged since its inception to ensure reliability. The UL database which contains data from these diagnostic tests dating from 1998 to 2014 currently holds information on over 10,700 students. This study includes the data of 4028 incoming students between the years $2009-2014$ with a range of 633 students in 2014 and of 739 students in 2012. 


\section{Qualitative Section}

Individual interviews were conducted with five mathematics teachers to determine their views on adopting the functions based approach when teaching algebra. These interveiws also gave the authors the opportunity to discuss the quantitative data with these key stakeholders in more detail. All of the participating teachers were fully qualified Irish secondary mathematics teachers with between eight and twelve years of experience in teaching the subject. Seven teachers from seven different schools in the greater Dublin area were originally approached to take part in the study having been selected using a purposive sampling method. The criteria for inclusion were male and female mathematics teachers with between seven and fifteen years teaching experience in co-educational schools in the Dublin region. Their years' of experience were important as the authors wanted to interview teachers who had taught mathematics pre and post the reform period. Five of the seven teachers (three male and two female) who were originally approached agreed to take part in the study. The interviews were conducted by one of the authors who had no previous personal or professional relationship with any of the participants.

Data collection took place between February 2015 and April 2015. Interviews were semi-structured in nature and lasted between 25 and 45 minutes. The interviews were digitally recorded and subsequently transcribed verbatim. Participants were identified by a letter and a number, for example T1 (Teacher 1) and all personal name and place name identifiers were removed from each transcript. There were four main questions around which each of the interviews were structured:

- How do you find the functions based approach to teaching algebra that has been adopted through Project Maths?

- What do you find are the main changes of the functions based approach? 
- Our study found that there has been a decline in incoming university students' fundamental rule and procedure based algebraic skills in recent years. What do you think are the main reasons for this?

- What can be done at secondary level to improve the teaching and learning of algebra?

The interview data was analysed using a thematic content analysis. Although this study did not involve a large amount of qualitative data it was decided that both authors would carry out the analysis to increase comprehensibility and to provide sound interpretation of the data. A coding scheme was generated based on a mixed deductive and inductive approach. On the one hand, codes were derived theoretically, taking into account the research questions and the results of the quantitative data. On the other hand, themes were identified from the transcripts, providing the basis for generating new codes or modifying the existing codes. Each of the authors worked separately on the transcripts, which made the assessment of consistency between their coding mandatory. The coding of each transcript was compared consecutively and any discrepancies were discussed. The final coding scheme consisted of three major codes which were each partially divided into subcodes. The three major codes include the adoption of the functions based approach, the problems with the teaching and learning of algebra and how these problems could be addressed. The coding scheme was used to capture and provide a basis for the quantification of a range of themes which provide much insight into teachers' views on the adoption of the functions based approach.

\section{Results}

\section{Quantitative Data}


Initial analysis of the data found that overall there was a statistically significant difference $(t=5.618, p<0.001)$ between the mean scores of the eight algebra questions from the 2009 - 2011 cohort (M: 57.95; SD: 36.62) compared to the 2012 - 2014 cohort (M: 52.875; SD: 36.53) (Figure 1).

Figure 1. Mean Scores of Eight Algebra Questions in 2009 - 2011 and 2012 - 2014

A closer look at data revealed the mean score of each of the eight algebra questions from both groupings (Figure 2). The findings expose a decline in performance in many of the questions in the years $2012-2014$ when compared to the previous three years of data. This decline is particularly evident in questions $14,17,18$ and 21.

Figure 2. Mean Score of Algebra Questions from 2009 - 2011 and 2012 - 2014

In directly comparing the 2009 - 2011 and 2012 - 2014 results, students who had been taught using the transformational based approach scored higher in seven of the eight algebra questions. There was a statistically significant decrease in the mean scores of students in six of the eight algebra questions (Q14, 15, 16, 17, 18, 21) in $2012-2014$ when compared to 2009 - 2011 (Table 1).

Table 1. Mean Score, Standard Deviation and Independent T-tests

\begin{tabular}{lccc}
\hline Question & Mean (SD) 2009-11 & Mean (SD) 2012-14 & Independent t-test \\
\hline $\mathbf{1 4}$ & $54(49.8)$ & $41(49.2)$ & $t=8.75, \quad p=.000$ \\
\hline $\mathbf{1 5}$ & $65(47.6)$ & $62(48.4)$ & $t=2.03, p=.043$ \\
\hline $\mathbf{1 6}$ & $83(37.7)$ & $80(40.1)$ & $t=2.58, \quad p=.01$ \\
\hline $\mathbf{1 7}$ & $63(48.3)$ & $53(49.9)$ & $t=6.46, p=.000$ \\
\hline $\mathbf{1 8}$ & $66(47.5)$ & $60(49.1)$ & $t=3.81, p=.000$
\end{tabular}




\begin{tabular}{lccc}
\hline $\mathbf{1 9}$ & $74(43.9)$ & $76(41.2)$ & $t=1.654, p=.098$ \\
\hline $\mathbf{2 0}$ & $32(46.7)$ & $31(46.2)$ & $t=0.78, p=.438$ \\
\hline $\mathbf{2 1}$ & $27(44.5)$ & $20(39.5)$ & $t=5.80, p=.000$
\end{tabular}

A closer inspection of the six algebra questions (Q14, 15, 16, 17, 18, 21) in which there were statistically significant decreases between the cohorts does not reveal any obvious connection between the questions (Table 2). Many of the questions involve skills which were highlighted as problematic in the Chief Examiner Reports (1999, 2003, 2006, and 2015). Question 14 involves the rearrangement of formula, Question 16 is solving a linear equation, Question 15 is substitution, Question 17 and 18 involve solving quadratic and simultaneous equations respectively and Question 21 concerns the subtraction of algebraic fractions. Similarly, no obvious connection appears to exist between the questions in which there were no statistically significant differences (Q19, 20). Question 19 involves the expansion of brackets while Question 20 concerns solving inequalities. Each of the eight questions are Junior Cycle Higher Level / Senior Cycle Ordinary Level standard and would have been on the traditional syllabus, in addition to being on the reformed syllabus.

Table 2. Comparing Mean Scores of Questions from 2012 - 2014 with 2009 - 2011

\begin{tabular}{llc}
\hline Question & & Changes \\
\hline $\mathbf{1 4}$ & Solve for $\mathrm{h}: V=\pi r^{2} h$ & $<$ \\
\hline $\mathbf{1 5}$ & Evaluate $a b+2 b c-3 a c$ when $a=$ & \\
& $3, b=-2$ and $c=4$. & $<$ \\
\hline $\mathbf{1 6}$ & Solve the equation: $3(\mathrm{x}+2)-24=0$ & \\
\hline
\end{tabular}




\begin{tabular}{lll}
\hline $\mathbf{1 7}$ & Solve for $\mathrm{x}: x^{2}+x-6=0$ & $<$ \\
\hline $\mathbf{1 8}$ & Solve the set of equations $2 x+y=7$ & \\
& $x+2 y=5$ & \\
& & \\
\hline $\mathbf{1 9}$ & Write out $(x+3 y)(a-2 b)$ in an & - \\
& equivalent form without brackets. & \\
\hline $\mathbf{2 0}$ & Solve for $\mathrm{x}: 3-6 x<21$ & $<$ \\
\hline Note: $\quad<=$ statistically significant decrease $\quad>=$ statistically significant increase
\end{tabular}

\section{Qualitative Data}

As mentioned in the methodology, the final coding scheme for the qualitative data consisted of three major codes which were each partially divided into sub-codes. The major codes and sub-codes are outlined in Table 3.

Table 3. Frequency of Themes in Teacher Interviews

\begin{tabular}{lcc}
\hline Theme & Frequency $(\mathrm{n}=180)$ & $\%$ \\
\hline Adoption of the functions based approach & $\underline{57}$ & $\underline{32}$ \\
- Unsuccessful implementation & 27 & 15 \\
- Reverting to traditional style & 12 & 7 \\
- Mixture in approaches & 9 & 5 \\
- No link between algebra and functions & 9 & 5 \\
\hline Problems with teaching and learning of algebra & $\underline{72}$ & $\underline{40}$ \\
- Neglect of skills & 18 & 10 \\
- Lack of time & 21 & 12 \\
\hline
\end{tabular}




\begin{tabular}{lcc}
\hline - Workload of new curriculum & 15 & 8 \\
- Over emphasis on problem solving & 12 & 7 \\
- Low emphasis on algebra in exam papers & 8 & 3 \\
\hline Addressing the problems & $\underline{51}$ & $\underline{28}$ \\
- Promote a balance between approaches & 18 & 10 \\
- More emphasis in examination papers & 6 & 3 \\
- Further professional development & 15 & 8 \\
- Consistency with primary level & 12 & 7 \\
\hline Total & 180 & 100 \\
\hline
\end{tabular}

One of the main themes that emerged from the interviews was the unsuccessful adoption of the functions based approach in some schools of the participating teachers (T3: I don't think the functions based method is being fully implemented anyway; T4: From my experience the change to a function based approach isn't really happening on the ground). The data revealed that in many cases the functions based approach is used when algebra is being first introduced but then the teachers revert to the traditional style (T5: In our maths department there may be a bit of looking at patterns at the beginning [when introducing], but then it's very much the traditional rule based methods of the old course before moving onto the applications and problem solving). This has resulted in a mixture between both approaches (T3: You're stuck in the middle, you're not doing the functions approach but you're also not doing as much procedure based work and practice as you would have done before).

In some cases the functions based approach is non-existent in some of the teacher's schools and no link is made between algebra and patterns / functions in the teaching of mathematics (T1: The patterns and functions chapter is treated by itself and 
isn't really linked to algebra. I don't teach algebra the functions way or anything like that; T2: You're talking about patterns. That's different. We do algebra first and then we do patterns afterwards).

The teachers who were interviewed did recognise problems with the teaching and learning of algebra since the introduction of the reformed curriculum and algebra strand. Four main reasons emerged from the data. The first three were noticeably interlinked. Many felt that the fundamental rule and procedure based algebraic skills were being neglected (T2: The skills are being hugely neglected. It's all problem solving mainly now. I would fly through the basics and try and have more time for the applications because that takes so much time, it's very new to the students). As alluded to by Teacher 2 in the previous comment, the skills are being neglected due to a lack of time. This was mentioned by each teacher in their individual interview (T1: You did so much practise on the old course on substitution, factorising etc. but the time isn't just there to do that anymore; T5: At the moment we don't really know how much time we can spend on practising the skills as we are so concerned about moving onto the applications). This time was already restricted as a result of the workloads and timeframe of the new curriculum (T3: The amount of material that has to be covered with the timeframe involved makes it very difficult). However as referred to in previous comments, the neglect of the fundamental algebraic skills due to the lack of time is also a result of the emphasis now being placed on problem solving and applications in the new curriculum (T2: The students are focusing way more on the practical problems and the applications and they're getting bogged down on them and they're not focusing as much on their basic skills. We are not spending as much time on them and as a result they're not fully grasping the basic methods). 
The teachers interviewed indicated that change was required regarding the current teaching, learning and assessment of algebra at secondary level in Ireland. Some spoke of the need for balance between the applications of algebra and its technical skills and to ensure sufficient time is devoted to both (T3: There must be more of a balance between applications and the skills. You have to give the time to the skills as well and this will make them more confident anyway using those skills when they are doing the problem solving). The need for more of an emphasis on the fundamental algebra skills in examination papers was highlighted (T1: There perhaps need to be a small bit more of an emphasis on the skills in the exam papers. The skills section is very short. Only six short questions, only 150 points. Then it's all application and problem solving based. They're forgetting to test the basic maths skills even though it's a maths exam).

In terms of promoting the functions based approach to teaching algebra, responses noted the need for more training to be provided to mathematics teachers highlighting effective pedagogy for using the approach (T3: More in-service on the functions based approach and more structure on to how to teach using it. I think we're in that transitory period where teachers are trying to do new things but they're not really sure what they are doing or supposed to be doing). The point was also made that in order for the functions based approach to be effective then it also needs to be adopted at primary school level (T4: If the functions / pattern based approach is to make a successful transition then students need to be introduced to it at primary level. There's too much disconnect at the moment between primary and secondary maths and the approaches being used).

\section{Discussion}


The analysis of the UL diagnostic test results shows that there are statistically significant declines in the 2012 - 2014 mean algebra scores of students when compared to 2009 2011. These declines have coincided with the introduction of a functions based approach to teaching algebra in Irish classrooms. It could be argued that these findings are hardly surprising given that the diagnostic test used to gather the data focuses solely on transformational activities and the emphasis on such activities may have diminished under the reformed curriculum. However the eight algebra questions contained in the test are of a fundamental standard and all Irish students would have encountered such concepts at lower / upper secondary school. Thus the results of this study, in this regard, are surprising. Whatever the approach to teaching algebra at secondary level, the authors feel that students entering third level on undergraduate degree programmes with a mathematics component, should be competent in rearranging formulae, expanding brackets, substitution and solving linear and quadratic equations. These skills have long been a hallmark of algebraic proficiency (Kieran, 1992; Yerushalmy \& Chazan, 2002) and are the cornerstone of many other areas of mathematics. The authors argue that such skills should be acquired by secondary level students regardless of whether they are being taught algebra using a transformational, a functions based or indeed any other approach. The knowledge base remains important and anyone who lacks a solid grasp of the procedures and concepts is significantly disadvantaged in mathematics (Schoenfeld, 2007).

It is important to note that the authors of this study are not making a case for the failure of the functions based approach in Irish classrooms at this early stage. They are of the opinion that this approach is the way forward for giving meaning to the objects and processes of algebra while at the same time developing students' algebraic skills. This is supported by Schoenfeld (2007) who argued that students who study more broad based 
curricula tend to do well on tests of skill and on tests of student understanding and problem solving. While the quantitative findings of this study contradict both the authors' and Schoenfeld's argument in terms of students' skills, the qualitative findings shed light on the possible reasons for this.

\section{Differences between the Intended and the Implemented Curriculum}

The main reason would appear to be differences between the intended 'Project Maths' curriculum and the one that is currently being implemented by teachers in their classrooms. Each of the teachers interviewed in this study felt that the newly adopted approach was not being implemented properly in their schools. $15 \%$ of the qualitative responses referred to the unsuccessful implementation. For some it depended on the class teacher, for others it was the class group 'What approach you use depends on the group. I would still tend to use a very rule based approach with my weaker classes. With my stronger classes, I would try to link algebra much more with functions and graphs etc.'

(Teacher 3). Two teachers went as far to say that there was no change to teaching algebra in their schools since the introduction of the reformed strand. These statements correspond with the findings of Jeffes et al. (2013) who noted that since the reform there does not appear to be a substantial shift in what teachers are asking students to do and that traditional approaches to mathematics teaching continue to be widespread. This also supports the work of Lubienski (2011) who found that there was resistance to the changes by many teachers. Such resistance, which is evident in the qualitative findings of this study, is worrying given that teachers are the key agents of any educational change (Kärkkäinen, 2012; Schoenfeld, 2014).

Possible Reasons for Teachers failure to adopt the Functions Based Approach 
The qualitative data also offered some insights into why some teachers are not implementing the new mathematics programme as intended. As far back as 1975, Lortie determined that teachers are often reluctant to adopt new practices or procedures unless they feel sure they can make them work. This is summed up by Teacher 2 who reverted to the 'old rule model because the the kids aren't really grasping it [the functions based approach]'. This lack of confidence in using the functions based approach highlights the importance of professional development for teachers in any reform, but particularly in Ireland where, in a 2009 study, nearly half of all secondary mathematics teachers at that time were deemed not to be sufficiently qualified to teach the subject (Ni Riordain \& Hannigan, 2011). The teaching approaches advocated by 'Project Maths' require a much firmer knowledge of mathematics as teachers are required to step away from the textbook and to make subtle connections between different elements of mathematics (Prendergast et al., 2014b). Mathematics teachers, qualified or unqualified, are unlikely to do this when they have only been schooled in narrow instrumental approaches to algebra and symbol manipulation techniques (Blanton \& Kaput, 2008).

Over the course of the 'Project Maths' implementation period, mathematics teachers in Ireland received ten national day-long workshops to inform them and develop their knowledge of the curricula changes. These workshops explored the different pedagogical approaches and content changes over the five strands of the reformed curricula. Consequently, only one workshop focused on the functions based approach to algebra. This is despite research highlighting secondary mathematics teachers' fragile understanding of the concept of a function (Doerr, 2004). Therefore it is unsurprising that teachers in this study reported that they are 'not really $100 \%$ sure what to do'. Further and on-going professional development targeting the new teaching approaches needs to be provided for mathematics teachers. This is supported by Cosgrove et al.'s (2012) report 
which found that Irish mathematics teachers want more in-service around 'Project Maths'.

\section{Possible Reasons for the decrease in Students' Transformational Algebraic Skills}

Previously in this paper the authors made the point that incoming third level students should be competent in basic technical algebraic skills regardless of whether they had being taught using a transformational, a functions based or indeed any other approach. Thus the question arises as to how the decreases in students' transformational skills (as evidenced in the diagnostic results) have come about. From a wider perspective the qualitative data revealed that teachers are not spending as much time on teaching algebra since the introduction of 'Project Maths' (T2:In the old Leaving Cert maths course you'd probably be doing algebra up until Christmas. For Project Maths, certain textbooks give a timeline that teachers are supposed to follow and they only give you 7-9 weeks for algebra so you're actually scrapping 6 weeks off there). This in itself is problematic given the strong, positive correlations between instruction time and student knowledge and skill development in education (Smith, 2000).

However more specifically the authors contend that the main reasons for the differences in students' transformational skills are linked to those already described regarding the unsuccessful implementation of the functions based approach to teaching algebra. This has resulted in a mixture between different approaches (T3: You're stuck in the middle). A properly implemented functions based approach does not advocate a neglect of students' fundamental algebraic skills. However unsuccessful implementation has led teachers of this study to place an over-emphasis on problem solving and applications and this has led to concern that students might be losing out on the skills. This is an important finding that needs to be addressed given that transformational 
algebraic activities are a central component of algebra curricula (Ayalon \& Even, 2015). While the focus on the applications and problem solving activities of algebra is a welcome move, it is also important that the algebraic purpose behind such activities is not lost. This was evidenced in the U.K. in the early 1990's where the search for meaning and the consequent suppression of symbolism led to a situation where students were doing hardly any symbol manipulation (Sutherland, 1997).

\section{Implications of this Study}

A 'balance between applications and skills' was mentioned by one of the teachers interviewed in this study as a possible way forward. The challenge for the future is giving meaning not only to the objects of algebra but also to its manipulative processes. Sure, there must be a shift from traditionally taught classes, but not to one which completely bypasses symbol manipulation and rule based procedures. Supporting the work of Ayalon and Even (2015), the authors of this study are emphasising that transformational activities do not need to be taught in isolation, nor do they need to be confined to following rules and rote symbol manipulation. For example, students can encounter how to simplify expressions and substitute variables within problem solving functions based contexts. In this way techniques and conceptual understanding can be taught together rather than in opposition to each other. A model for such a balance was designed and developed by Kieran (1996) in which teachers are encouraged to place emphasis on different types of activities when teaching school algebra.

However, more importantly, and from a general education viewpoint, this study extends our understanding of the challenges associated with successfully implementing curriculum reform. Carless (1999) notes that "if teachers are to implement an innovation, it is essential that they have a thorough understanding of the principles and practices of 
the proposed change" (p. 355). The responses of the teachers interviewed in this study indicate that they did not understand the curriculum in such a way. This highlights the need for more professional development for teachers before and during the implementation of any curriculum innovation to ensure a 'shared vision' of the reform is held by all parties. A 'bottom-up' approach to curriculum reform must be promoted which takes into account teachers' concerns and beliefs. They are the ones who are tasked with translating intentions into practice and ultimately deciding the fate of the reform.

\section{Conclusion}

The findings of this study highlight that there are many continuing challenges in successfully implementing educational reform and turning policy into practice. This research focused on the topic of algebra, but the findings could be relevant to any curriculum innovation, in any subject area. With specific reference to algebra, there has been a need to reconceptualise the domain to show its usefulness and to give students a clearer idea of its relevance beyond symbol manipulation (Stacey \& Chick, 2004). This need has been the stimulus for many experimental teaching approaches and curricula reforms such as the recent adoption of the functions based approach in Irish secondary classrooms. In addressing the research questions set out for this study, the quantitative results of the UL diagnostic test scores highlight that there has been a decline in students' transformational algebraic skills between the years $2012-2014$. However the responses of the teacher interviews stress that this is not a direct result of the functions based approach, but rather of a mixture of approaches being used and students neglecting their algebraic skills due to a lack of time due to the emphasis now placed on problem solving and applications. 
Thus the task for Irish mathematics educators on the basis of this study is to ensure that there is a uniform approach and structure to teaching algebra in all schools and across all levels. If this is to be the functions based approach as advocated by the recent curriculum reform, a further challenge lies in ensuring that teachers are fully knowledgeable and confident on how to implement it successfully in their classrooms. Only then can the mismatch between the intended curriculum and the implemented curriculum be addressed.

\section{References}

Ayalon, M., \& Even, R. (2015). Students Opportunities to Engage in Transformational Algebraic Activity in Different Beginning Algebra Topics and Classes. International Journal of Science and Mathematics Education, 13, 285-307. doi:10.1007/s10763013-9498-5

Blanton, M.L. (2008). Algebra and the Elementary Classroom: Transforming Thinking, Transforming Practice. Portsmouth: Heinemann.

Blanton, M. L., \& Kaput, J. J. (2008). Building district capacity for teacher development in algebraic reasoning. In J. J. Kaput, D. W. Carraher, \& M. L. Blanton (Ed.), Algebra in the early grades (pp. 361-388). New York: Taylor and Francis Group.

Carless, D. R. (1999). Perspectives on the cultural appropriacy of Hong Kong's targetoriented curriculum (TOC) initiative. Language Culture and Curriculum, 12, 238-254. doi:10.1080/07908319908666581

Chief Examiners Report (1999; 2003; 2006; 2015). Junior Cert Examinations Mathematics. Retrieved from http://www.examinations.ie

Chazan, D. (2000). Beyond formulas in mathematics teaching: Dynamics of the high school algebra classroom. New York: Teachers College.

Chazan, D., \& Yerushalmy, M. (2003). On appreciating the cognitive complexity of school algebra: Research on algebra learning and directions of curricular change. In J. Kilpatrick, D. Schifter, \& G. Martin (Ed.), A Research Companion to the Principles and Standards for School Mathematics (pp. 123-135). Reston, Virginia: NCTM.

Cosgrove, J., Perkins, R., Shiel, G., Fish, R., \& McGuinness, L. (2012). Teaching and Leaning in Project Maths. Dublin: Educational Research Centre. 
Cuban, L. (1993). The lure of curricular reform and its pitiful history. The Phi Delta Kappan, 75, 182-185. Retrieved from http://www.jstor.org/stable/20405055?seq=1\#page scan tab contents

Doerr, H. (2004). Teachers' knowledge and the teaching of algebra. In K. Stacey, H. Chick, \& M. Kendal (Ed.), The Future of the Teaching and Learning of Algebra - The $12^{\text {th }}$ ICMI Study (pp. 267-290). London: Kluwer Academic Publishers.

Duke, D. L. (2004). The challenges of educational change. Boston: Allyn \& Bacon.

Faulkner, F. (2012). An Analysis of Performance in Mathematics for Technology Undergraduates and an Investigation of Teaching Interventions for these Students (Unpublished doctoral dissertation). University of Limerick, Ireland.

Faulkner, F., Hannigan, A., \& Fitzmaurice, O. (2014). The role of prior mathematical experience in predicting mathematics performance in higher education. International Journal of Mathematical Education in Science and Technology, 45, 648-6. doi:10.1080/0020739X.2013.868539

Fullan, M., \& Hargreaves, A. (1992). Understanding Teacher's Development. Teachers College, Columbia University.

Freudenthal, H. (1977). What is algebra and what has it been in history? Archive for History of Exact Sciences, 16, 189-200. doi:10.1007/BF00328154

Gill, O., O’Donoghue, J., Hannigan, A., \& Faulkner, F. (2010). Trends in Performance of Science and Technology Students (1997-2008) in Ireland. International Journal of Mathematical Education in Science and Technology, 41, 323-339. doi: $10.1080 / 00207390903477426$

Guskey, T. R. (1986). Staff development and the process of teacher change. Educational researcher, 15, 5-12. doi:10.3102/0013189X015005005

Handal, B., \& Herrington, A. (2003). Mathematics teachers' beliefs and curriculum reform. Mathematics education research journal, 15, 59-69. doi:10.1007/BF03217369

Huntley, M.A., Marcus, R., Kahan, J., \& Lincoln Miller, J. (2007). Investigating highschool students' reasoning strategies when they solve linear equations. The Journal of Mathematical Behaviour, 26, 115-139. doi:10.1016/j.jmathb.2007.05.005

Jeffes, J., Jones, E., Wilson, M., Lamont, E., Straw, S., Wheater, R., \& Dawson, A. (2013). Research into the impact of Project Maths, Slough: NFER. 
Karkkainen, K. (2012). Bringing about Curriculum Innovations. OECD Education Working Papers, No. 82. OECD Publishing (NJ1).

Kieran, C. (1992). The Learning and Teaching of School Algebra. In D. Grouws (Ed.), Handbook of research on mathematics teaching and learning (pp. 390-419). New York: Macmillan Publishing Company.

Kieran, C. (1996). The Changing Face of School Algebra. In 8th International Congress on Mathematical Education, Selected Lectures (pp. 271-286). S.A.E.M. THALES.

Kieran, C. (2014). Algebra teaching and learning. In S. Lerman (Ed.), Encyclopaedia of Mathematics Education (pp. 27-32). Dordrecht, The Netherlands: Springer Reference.

Kilpatrick, J., \& Izsák, A. (2008). A history of algebra in the school curriculum. In C.E. Greenes and R. Rubenstein (Ed.), Algebra and algebraic thinking in school mathematics: Seventieth yearbook (pp. 3-18). Reston, VA: The National Council of Teachers of Mathematics.

Klein, D. (2007). A quarter century of US 'math wars' and political partisanship. BSHM bulletin: Journal of the British Society for the History of Mathematics, 22, 22-33. doi:10.1080/17498430601148762

Koyama, M. (2010). Mathematics curriculum in Japan. In F. K. S. Leung \& Y. Li (Ed.), Reforms and issues in school mathematics in East Asia: pursuing excellence in mathematics curriculum and teacher education (pp. 59-78). Rotterdam: Sense Publishers.

Krupa, E. E., \& Confrey, J. (2015). Effects of a reform high school mathematics curriculum on student achievement: for whom does it benefit?.Journal of Curriculum Studies, 49, 191-215. doi:10.1080/00220272.2015.1065911

Kyeleve, J. I., \& Williams, J. (1996). Measures of teachers' attitudes towards mathematical modelling. In Psychology of Mathematics Education Conference (Vol. 3, pp. 3-209). The Programme Committee of the $18^{\text {th }}$ PME Conference.

Lannin, J. K., Barker, D.D., \& Townsend, B.E. (2006). Recursive and explicit rules: How can we build student algebraic understanding? Journal of Mathematical Behavior, 25, 299-317. doi:10.1016/j.jmathb.2006.11.004

Levitt, K. (2001). An analysis of elementary teachers' beliefs regarding the teaching and learning of science. Science Education, 86, 1-22. doi:10.1002/sce.1042

Ley, A. F. (2005). A cross-sectional investigation of elementary school student's ability to work with linear generalizing patterns: The impact of format and age on accuracy 
and strategy choice (Unpublished doctoral dissertation). University of Toronto, Canada.

Liu, J., \& Li, Y. (2010). Mathematics curriculum reform in the Chinese mainland: changes and challenges. In F. K. S. Leung \& Y. Li (Ed.), Reforms and issues in school mathematics in East Asia: pursuing excellence in mathematics curriculum and teacher education (pp. 9-31). Rotterdam: Sense Publishers.

Lortie, D. C. (1975). School teacher. Chicago: University of Chicago Press.

Lubienski, S. T. (2011). Mathematics Education and Reform in Ireland: An Outsiders Analysis of Project Maths. Bulletin of the Irish Mathematical Society, 67, 27-55. Retrieved from http://www.maths.tcd.ie/pub/ims/bull67/2011-1-10.pdf

Lyons, M., Lynch, K., Close, S., Sheerin, E., \& Boland, P. (2003). Inside ClassroomsThe Teaching and Learning of Mathematics in the Social Context. Dublin: Institute of Public Administration.

Manouchehri, A., \& Goodman, T. (1998). Mathematics curriculum reform and teachers: Understanding the connections. The Journal of Educational Research, 92, 27-41. doi:10.1080/00220679809597573

National Council for Curriculum and Assessment (2005). Review of Mathematics in Post - Primary Education. Dublin: The Stationary Office.

National Council of Teachers of Mathematics (1989). Principles and standards for school mathematics. Reston, VA: Author.

National Mathematics Advisory Panel (2008). Foundations for success: The final report of the National Mathematics Advisory Panel. Washington, DC: U.S. Department of Education.

Ní Ríordáin, M., \& Hannigan, A. (2011). Who teaches mathematics at second level in Ireland? Irish Educational Studies, 30, 289-304. doi:10.1080/03323315.2011.569117

Orafi, S. M. S., \& Borg, S. (2009). Intentions and realities in implementing communicative curriculum reform. System, 37, 243-253. doi:10.1016/j.system.2008.11.004

Prendergast, M., Faulkner, F., Breen, C., \& Carr, M. (2017). Mind the Gap: An Initial Analysis of the Transition of a Second level Curriculum Reform to Higher Education, Teaching Mathematics and its Applications. doi:10.1093/teamat/hrw024.

Prendergast, M., Johnson, P., Fitzmaurice, O., Liston, M., O’Keeffe, L., \& O’Meara, N. (2014b). Mathematical thinking: challenging prospective teachers to do more than 
'talk the talk'. International Journal of Mathematical Education in Science and Technology, 45, 635 - 647. doi:10.1080/0020739X.2013.868538

Prendergast, M., \& O’Donoghue, J. (2014a). 'Students enjoyed and talked about the classes in the corridors': pedagogical framework promoting interest in algebra. International Journal of Mathematical Education in Science and Technology, 45, 795812. doi:10.1080/0020739X.2013.877603

Prendergast, M., \& O’Meara, N. (2016). A profile of mathematics instruction time in Irish second level schools. Irish Educational Studies. doi:10.1080/03323315.2016.1229209

Prendergast, M., \& Treacy, P. (2015). Analysing Ireland's Algebra Problem. In CERME 9-Ninth Congress of the European Society for Research in Mathematics Education (pp. 460-466).

Scheker-Mendoza, A. (2011). Educational Reform and Teachers' Decision Making: Relationship between the Intended and the Implemented Reading Curriculum in Dominican Primary Schools (doctoral dissertation). State University of New York at Albany, United States.

Schoenfeld, A. H. (2007). What is Mathematical proficiency and how can it be assessed? In A.H. Schoenfeld (Ed.), Assessing mathematical proficiency (pp. 3-15). Cambridge, UK: Cambridge University Press.

Schoenfeld, A.H. (2014). Reflections on curricular change. In L. Yeping and G. Lappan (Ed.), Mathematics Curriculum in School Education (pp. 49-72). Netherlands: Springer.

Smith, B. A. (2000). Quantity Matters: Annual Instruction Time in an Urban School System, Educational Administration Quarterly, 36, 652-682. doi:10.1177/00131610021969155

Smith, L. K., \& Southerland, S. A. (2007). Reforming practice or modifying reforms? Elementary teachers' response to the tools of reform. Journal of Research in science Teaching, 44, 396-423. doi:10.1002/tea.20165

Stacey, K., \& Chick, H. (2004). Solving the problem with algebra. In K. Stacey., H. Chick, \& M. Kendal (Ed.), The Future of Teaching and Learning of Algebra. The $12^{\text {th }}$ ICMI Study (pp. 1-20). London: Kluwer Academic Publishers.

Sutherland, R. (1997). Teaching and Learning Algebra pre - 19. Report of a Royal Society/ JMC Working Group. Retrieved from http://royalsociety.org/displaypagedoc.asp? id=11493 
Tanish, D. (2011). Functional thinking ways in relation to linear function tables of elementary school students. The Journal of Mathematical Behavior, 20, 206-223. doi:10.1016/j.jmathb.2011.08.001

Treacy, P., Faulkner, F., \& Prendergast, M. (2016). Analysing the correlation between secondary mathematics curriculum change and trends in beginning undergraduates' performance of basic mathematical skills in Ireland. Irish Educational Studies, 35, 281-401. doi:10.1080/03323315.2016.1243067

Yerushalmy, M., \& Chazan, D. (2002). Flux in school algebra: Curricular change, graphing technology, and research on student learning and teacher knowledge. In L. English (Ed.), Handbook of International Research in Mathematics Education (pp. 725-755). Hillsdale, NJ: Erlbaum.

Ma, Y., Lam, C., \& Wong, N. (2006). Chinese primary school mathematics teachers working in a centralised curriculum system: a case study of two primary schools in North-East China. Compare, 36, 197-212. doi:10.1080/03057920600741206 